Journal of Patient-Centered

Volume 8

Issue 4 - Cancer Screening

Article 11

10-18-2021

\title{
In Pursuit: A Mother's Account of Her Son's Rare Disease Diagnosis Journey
}

Anne M. Jones

Follow this and additional works at: https://aah.org/jpcrr

Part of the Congenital, Hereditary, and Neonatal Diseases and Abnormalities Commons, Medical Humanities Commons, Nervous System Commons, Nervous System Diseases Commons, and the Neurology Commons

\section{Recommended Citation}

Jones AM. In pursuit: a mother's account of her son's rare disease diagnosis journey. J Patient Cent Res Rev. 2021;8:360-2. doi: 10.17294/2330-0698.1845

Published quarterly by Midwest-based health system Advocate Aurora Health and indexed in PubMed Central, the Journal of Patient-Centered Research and Reviews (JPCRR) is an open access, peer-reviewed medical journal focused on disseminating scholarly works devoted to improving patient-centered care practices, health outcomes, and the patient experience. 


\section{In Pursuit: A Mother's Account of Her Son's Rare Disease Diagnosis Journey}

Anne M. Jones, MS, OTR*

${ }^{*}$ Author is a parent of the patient whose health care experiences are described in this article

$\mathrm{M}$ $\mathrm{y}$ husband and I welcomed our third son in 2013. The pregnancy had progressed normally except for a subchorionic hemorrhage that occurred and resolved within the gestational time frame of weeks $8-12$. His due date also had been moved up 9 days due to larger gestational size. He arrived via vaginal delivery, with oxytocin injection (Pitocin) and an epidural assisting during labor. My son "roomed in" with me during our stay in the hospital, and we went home not realizing anything was atypical.

The first clues that something was wrong came when my son was around 4-6 months old. We had started baby food per his pediatrician's recommendation, and he immediately became constipated. I called the nurse describing the situation and was reassured this was normal for breastfed babies, but his long bouts between bowel movements seemed unusual. Another clue that something was amiss was that my son was not progressing normally in his gross motor milestones. He flopped over in sitting, and rolling was nonexistent. The pediatrician and I agreed that I would do some exercises at home until his 9-month well-child check. I am an occupational therapist, and my firstborn had previously done physical therapy around the same age, so I felt comfortable with the plan. By 9 months, despite a summer filled with tummy time and exercises, he still was not sitting or rolling.

At his 9-month well-child check, the physician assistant mentioned the possibility of additional tests and my husband and I agreed to biweekly physical therapy. As a parent, this was the first time that alarm bells began sounding in my head. The next week, my pediatrician and I talked and again he reassured me he did not feel anything was wrong beyond what physical therapy could remedy. We were planning to move across the country in a few months and so agreed to continue the course of physical therapy and check in with our new pediatrician after the move.

Corresponding author: Anne M. Jones,

Fort Mill, SC (anne.baumgardner@gmail.com)
At 12 months, after the move and 3 months of biweekly physical therapy, my son was now rolling but still unable to sit up independently. Due to his continued gross motor delays, my son's new pediatrician and I agreed it was time to pursue a neurology consult. The neurologist diagnosed my 13-month-old son with hypotonia and gross motor delays. I also described a nystagmus I had been noticing when nursing. From neurology we were referred to the state Birth to 3 Program as well as neuro-ophthalmology and genetics. His first magnetic resonance imaging (MRI) at 14 months showed "nonspecific findings." Since I had to wait until my next neurology appointment (which was 6 months away) to find out what that actually meant, I asked and was granted an appointment right away with a different neurologist. My son's MRI showed "prominent T2 hyperintensity and restricted diffusion involving the central tegmental tract," a finding the neurologist thought "could just be related to age/immature myelination." She went so far as to suggest that maybe he just had "third child syndrome." I was thankful nothing serious had shown up on his MRI but still disheartened by the lack of insight into the cause of my son's challenges.

At 15 months, my son began early intervention — speech and physical therapy services - through the state Birth to 3 Program. Occupational therapy was added several months later. His speech was significantly delayed, with minimal sounds and words that were not consistent. His receptive language seemed much higher than expressive. A hearing check with audiology came back normal. Neuro-ophthalmology diagnosed a horizontal nystagmus that had emerged with tracking to the far right and left horizontal planes and a slightly higher null point of vision. At 18 months, he started to sit independently but any loss of balance resulted in a fall due to delayed protective reactions. He was beginning to stand holding onto a surface but not yet cruising. He crawled at 19 months and got his first pair of orthotics at 20 months due to hypermobile ankles. Sleep was an issue. As an infant and toddler, he would wake upwards of 5 times per night. Once he finally started "sleeping" through the night, he would move all over his bed. All of these issues led my husband and I to feel that we were dealing with more than just something our son would "outgrow" over time. 
At 20 months, we drove over an hour to see our first clinical geneticist. She decided to do a blood draw for creatine phosphokinase, a chromosome microarray, and tests for Fragile $\mathrm{X}$ and myotonic dystrophy. The next month, we visited our third neurologist (the previous two had retired and left the area, respectively). During the visit, the neurologist assured us he would continue to search for answers, including the potential for whole exome sequencing. However, at our follow-up appointment 4 months later, given that the microarray and other tests came back normal, his physician assistant relayed that they were no longer pursuing a diagnosis unless my son regressed since the treatment (therapy) would be the same. I had previously left specialist appointments feeling frustrated with the lack of answers. But to hear your child's neurologist say that they would not do anything more now to help your 2-year-old son, who is a constant fall risk and struggles to communicate daily, was especially hard to take in. I went home that night and began my own research into alternative options for undiagnosed children.

The following day I had an appointment with my son's pediatrician. I discussed with him my frustration and next steps. I brought up the Undiagnosed Disease Network (UDN), ${ }^{1}$ a potential option for pursuing a diagnosis that I had found online. He recommended getting another opinion first and was instrumental in finding a different neurologist that would help us move forward. At our appointment, our fourth neurologist sat down with us for an hour and took notes and I felt truly heard for the first time. She referred my son to a different clinical geneticist, this time in our own health system, and we began a series of metabolic tests followed by tests for Prader-Willi syndrome and mitochondrial disorders. We also visited a pediatric neuromuscular specialist at an academic center several hours away. A repeat MRI at 29 months of age showed the same result as his first. When we were still left without answers, we pursued whole exome sequencing in October 2016, a month before my son turned 3 years old. I felt sure we would get an answer from that.

In April 2017, my son's preschool teacher pulled me aside one day and told me they suspected he was having potential absence seizures. The next day I took him for a clinical routine electroencephalogram (EEG) followed by an ambulatory EEG, both of which came back abnormal. We were referred to our fifth pediatric neurologist who specializes in epilepsy and a series of 24-hour EEGs at a local hospital showed bilateral centroparietal and centrotemporal spikes more pronounced in sleep. Thankfully, at the time of this writing, he has not yet had a convulsive seizure, but we run a seizure camera at night and carry emergency seizure medication as a precaution.
That same April, the whole exome sequencing results arrived. They were inconclusive. There was one gene that was considered a de novo variant of unknown significance, but it was not known whether this gene variant could cause a neurodevelopmental disability given the lack of research on individuals with this rare variant. The gene was mitogen-activated protein kinase 8 interacting protein 3, or MAPK8IP3. With our son continuing to show significant balance deficits and delays in all areas, we desperately wanted to find answers to help us understand and better treat his condition. It was at this point we turned our hope to the UDN.

My son's clinical geneticist made the referral to the UDN, and we were accepted and completed a week of appointments when he was 4 years old. Another routine EEG and MRI continued to show the same results. My son was diagnosed with apraxia of speech and referred for Prompts for Restructuring Oral Muscular Phonetic Targets (PROMPT) speech therapy, ${ }^{2,3}$ which has helped him gain new sounds and better articulation. The UDN shared that the MAPK8IP3 variant found on his exome test was likely the cause of his delays. They informed us that MAPK8IP3 is highly expressed in the nerves of the brain and a change in this gene is likely to cause an effect. Moreover, we were told about a paper underway on MAPK8IP3 variants in the human population. I drove home with mixed emotions; on one hand we finally had a likely diagnosis, but I was left feeling alone not knowing anyone else with this variant.

In February 2019, the aforementioned paper was published and described 13 cases of MAPK8IP3 variants in the human population. ${ }^{4}$ The researchers also described how some of the MAPK8IP3 variants preserved in roundworms (C. elegans) impacted the build-up of lysosomes in axons of their nerves and how fast the roundworms swam in liquid. ${ }^{4} \mathrm{~A}$ second paper followed in April 2019, which detailed 5 more cases of MAPK8IP3 variants in humans. ${ }^{5}$ In October 2019 , we received a statement from the genetics lab confirming his MAPK8IP3 gene variant had been changed from "unknown" to "pathogenic." After 3 health systems, 5 neurologists, 2 geneticists and a week at the UDN, we had an official diagnosis less than a month shy of my son turning 6 years old.

By sharing my son's story, I hope to raise awareness for the undiagnosed community through my own unique experience of the journey. One of the things I wrestled with as a mom of an undiagnosed child is guilt. I went over everything about my pregnancy. My therapists gave me many different ideas of therapies, equipment, specialists, and holistic medicine to consider. We had to 
constantly decide what we could do with our schedule and funds while trying to help our son be safer and gain skills. My son's various specialist, equipment, therapy, and special education appointments meant finding a sitter or my other children coming along to the appointments. My husband took a week of vacation to be home with our other children while I took my son and his infant sister to the UDN. A significant amount of time was spent making phone calls to health care providers in addition to filling out paperwork. My husband and I tried to weigh how much was appropriate to put our child through with regard to testing and visits while preserving a high quality of life for him and a balanced family life for our other children.

The hardest part of this whole journey for me has been learning to live with the unknown. At every specialist appointment, I brought up anything that I thought could offer a clue toward diagnosis. I have felt a myriad of emotions, from hope and nervousness to sadness and frustration. Fortunately, I was introduced to several other mothers in my community who had similar diagnostic journeys with their children. Being able to laugh and cry over shared experiences with these mothers was significantly helpful for my own emotional well-being and as stress management while waiting for answers. An earlier answer would have decreased the guilt, time, and stress associated with the pursuit of a diagnosis while offering a clearer path to treatment.

At the time of this writing, my son is 7 years old. While he struggles with motor planning and coordination in all areas of his life, he continues to amaze us with his persistence and progress. He has a joyful personality and greatly enjoys playing with his friends and family. $\mathrm{He}$ is starting to read simple sentences and thrives in a structured environment. He flaps his hands and tilts his head to the right when he is happy and excited. He is still a major fall risk in standing, and he cannot walk more than 8 steps without a device before falling over. However, he now walks up to a mile in his posterior walker and 20 feet with a quad cane. He can speak in 5-word sentences, although his intelligibility, especially to strangers, is limited by his apraxia of speech. We recently found out he has central sleep apnea, which may have contributed to his restless sleep over the years. He is now on a bilevel positive airway pressure (BiPAP) ventilator, and while still restless some nights, his sleep quality has improved.
I also want to highlight the impact of pursuing answers through genetic testing. It is true that our son's treatment did not change. He still participates in physical, occupational, and speech therapy as well as special education for his cognitive delays. However, understanding why he has his challenges helps us better tailor his therapy and advocate for his needs. In 2020, when my son was 6 years old, we were able to connect with other families with children who also have a MAPK8IP3 variant, both in the United States and overseas. The group continues to grow and virtually meet several times a year. The group has been inspiring and helpful, both emotionally and practically.

Lastly, ongoing research into $M A P K 8 I P 3$ is attempting to characterize the protein, study the natural history of related disorders, and develop animal models and cell lines with the hope of advancing future therapeutic options. I am thankful for answers and hope, as there are individuals and families still waiting with little of either. My family is grateful to all those in the medical community who helped to make that possible and will continue to advocate for our son and for the rare and undiagnosed disease communities.

\section{Acknowledgments}

The author gratefully acknowledges $M A P K 8 I P 3$ family group members for their support and encouragement and the Wolverine Foundation for supporting research into MAPK8IP3.

\section{Personal Disclosure}

The author is a familial relative of the editor-in-chief of Journal of Patient-Centered Research and Reviews.

\section{References}

1. Undiagnosed Disease Network. About us. Accessed April 10, 2021. https://undiagnosed.hms.harvard.edu/about-us/

2. Hayden DA. The PROMPT model: use and application for children with mixed phonological-motor impairment. Advances in Speech-Language Pathology. 2006;8:265-81.

3. Dale PS, Hayden DA. Treating speech subsystems in childhood apraxia of speech with tactual input: the PROMPT approach. Am J Speech Lang Pathol. 2013;22:644-61. CrossRef

4. Platzer K, Sticht H, Edwards SL, et al. De novo variants in MAPK8IP3 cause intellectual disability with variable brain anomalies. Am J Hum Genet. 2019;104:203-12. CrossRef

5. Iwasawa S, Yanagi K, Kikuchi A, et al. Recurrent de novo MAPK8IP3 variants cause neurological phenotypes. Ann Neurol. 2019;85:927-33. CrossRef

(C) 2021 Advocate Aurora Health, Inc. 